\title{
Topofilia, conforto ambiental e o ruído urbano como risco ambiental: a percepção de moradores dos Setores Especiais Estruturais da cidade de Curitiba
}

\section{Topophilia, Environmental Comfort and Urban Noise as an Environmental Risk: The Perception of Residents in the Special Structural Sections of the City of Curitiba}

\author{
Angela RIBAS* \\ Aloisio SCHMID ${ }^{* *}$ \\ Eleusis RONCONI***
}

\begin{abstract}
RESUMO
O tema deste artigo é o ruído urbano, considerado atualmente como a terceira causa de poluição do planeta. No Brasil, embora exista legislação específica que determina os limites de emissão de ruídos e estabelece medidas de proteção para a coletividade, o que se constata é que os níveis do mesmo estão acima de valores recomendados. A exposição ao ruído pode acarretar alterações de diversas ordens nos seres humanos e, consequentemente, resultar em diminuição da qualidade de vida. Nosso objetivo foi estudar e compreender como se dá a percepção da poluição sonora pela população dos Setores Especiais Estruturais de Curitiba e a relação existente entre o som (ruído), a saúde (auditiva) e o ambiente (urbano). Para tanto, realizamos medições de níveis de pressão sonora em 100 pontos escolhidos aleatoriamente no locus da pesquisa e entrevistamos 100 moradores nos mesmos locais. Constatamos que os níveis de ruído dentro das residências que ladeiam os Setores Especiais Estruturais estão acima do recomendado legalmente. Os resultados das entrevistas mostram que a população percebe a presença do ruído em seus lares, é capaz de identificar suas causas (principalmente o tráfego de veículos) e efeitos (auditivos e não auditivos), porém, esta percepção não se faz contundente.
\end{abstract}

Palavras-chave: ruído; percepção; meio ambiente.

\section{ABSTRACT}

The theme of this article is the urban noise, considered nowadays the third cause of pollution of the planet. In Brazil, although specific laws exist, which determine the thresholds for noise emissions and

\footnotetext{
"Fonoaudióloga. Universidade Tuiuti do Paraná. Email: angela.ribas@utp.br

*** Engenheiro mecânico. Universidade Federal do Paraná. Email: iso@ufpr.br

*** Médica. Universidade Federal do Paraná. Email: eleusis@onda.com.br
} 
establishes protective measures to the population, one realizes that the noise levels of the different daily life activities are above the recommended ones. Noise exposure may lead to several disorders in human beings and consequently, result in decreasing quality of life. Our aim was, therefore, to study and understand how is noise pollution perceived by the Structural Special Sectors of Curitiba's population and the relationship between sound (noise), health (auditory) and the environment (urban). Sound level measurements were performed in 100 arbitrarily chosen spots in the place of the investigation and 100 residents were interviewed in the same places. With the measurements, we found the noise levels inside the residences of these Sectors to be above the legally recommended, being thus a risk factor to the exposed population. The results of the interviews have shown that people realize the presence of noise inside their homes and are able to identify the causes (mostly vehicles traffic) and effects (auditory and non-auditory), but this perception is not evident.

Key-words: noise; perception; environment.

\section{Interface entre saúde, ruído e qualidade de vida}

Atualmente, o conceito de qualidade de vida tem sido empregado em diferentes contextos, por exemplo, na área da saúde, na política, na área urbana e no meio ambiente. Na realidade, o que vemos são esforços de muitas ciências e cientistas na direção de anular, ou pelo menos minimizar, os efeitos da degradação do meio ambiente sobre a saúde das pessoas. Deparamo-nos com manifestações em diversos setores da comunidade, envolvendo o governo e organizações na busca pela promoção da saúde dos povos e pela preservação do meio ambiente.

Entendemos que qualidade de vida contempla saúde e meio ambiente, na medida em que estes dois pontos são reflexos do modo de vida de uma determinada comunidade. E é neste contexto que este artigo se insere. Com vistas à melhoria da qualidade de vida das populações que habitam grandes centros urbanos e estão expostas ao ruído, entendemos ser emergente a necessidade de se estudar e compreender como se dá a percepção da poluição sonora pela população e a relação existente entre som (ruído), saúde (auditiva) e ambiente (urbano), já que as cidades têm se mostrado um campo fértil para o desenvolvimento de problemas ambientais como a poluição sonora.

As cidades configuram-se como espaços complexos pelas características intrínsecas de urbanização e pelas imposições do global sobre o local. Atender os interesses de cada um desses níveis, local e global, indica uma disputa clara entre as infraestruturas que cada um demanda e investimentos distintos devem ser efetivados para que mudanças positivas caracterizem o bojo das cidades.

É neste contexto contemporâneo, complexo, mutável e com crescentes demandas que desenvolvemos este estudo, que se concentra no exame e na análise dos modos como se dá a percepção de uma forma invisível de poluição, que atinge populações de grandes centros, inclusive Curitiba: a poluição sonora.

Curitiba é uma cidade permeada de problemas inerentes ao processo de metropolização e urbanização. Os níveis de ruído urbano da cidade, de acordo com pesquisas realizadas (BARBOSA, 1992; ZANNIN, 2002; RIBAS, 2007), não estão dentro dos limites especificados legalmente, podendo causar prejuízos à saúde da população. Em diversas áreas mapeadas, sejam zonas residenciais, de serviços ou do setor estrutural, além do centro da cidade e região industrial, foi constatado que o ruído urbano enquadra-se num patamar grave e, em algumas situações, como "em pontos do setor estrutural próximo às vias rápidas, o volume chega à beira da saturação" (BARBOSA, 1992).

Sabemos, também, que o tráfego de veículos é a grande causa do ruído urbano em Curitiba, sendo que aqui se enquadram ruídos provenientes de veículos automotivos (carros, ônibus e caminhões), aeronaves e trens, e que os níveis de poluição sonora atingem seus maiores índices nas vias estruturais da cidade, em especial nos Setores Especiais Estruturais (SEE).

O objetivo desta pesquisa, a partir da caracterização da qualidade do ambiente sonoro da cidade de Curitiba, verificado por meio de medições de ruído urbano e a sua variabilidade (RIBAS, 2007), é determinar qual a percepção que as pessoas têm deste ambiente sonoro. Especificamente, neste artigo discutimos a percepção de um grupo de pessoas moradoras dos SEE a partir de três ideias centrais: o ruído urbano como fator de risco ambiental, conforto acústico ambiental e topofilia. 


\section{O ruído urbano como risco ambiental}

Vem crescendo mundialmente a consciência sobre os problemas ambientais. Os movimentos ecológicos e o aumento de denúncias de problemas causados pelo meio ambiente na saúde da população em geral colocaram em evidência a relação entre a saúde das pessoas e o meio ambiente.

$\mathrm{Na}$ época em que vivemos, o risco é constante. Nunca as ações humanas tiveram a possibilidade de atingir a humanidade e o planeta em escala tão avassaladora. Os ecossistemas do mundo inteiro, atualmente, são afetados em graus variáveis por poluição de vários tipos e, segundo a Organização Mundial da Saúde (OMS, 1980), depois da poluição da água e do ar, nada agride mais os sentidos humanos do que a poluição sonora. Neste contexto é que, em diversas regiões do planeta, há pessoas se dedicando ao estudo do ruído e seus efeitos sobre os indivíduos. Podemos inferir que o ruído configura-se, portanto, como risco na nossa sociedade.

Giddens (2002) comenta que a aferição do risco é muitas vezes imperfeita, pois requer precisão e quantificação difíceis de serem realizadas em instituições modernas, graças ao seu caráter mutável. O autor explica que a modernidade reduz o risco de certas áreas e modos de vida, porém introduz novos parâmetros de risco pouco conhecidos em épocas anteriores. É o caso do ruído.

Para Ponting (1995), a partir da Segunda Guerra Mundial, houve uma mudança nos processos industriais e, consequentemente, no tipo de poluição produzida. As máquinas desenvolvidas pelos homens, entre elas os veículos automotivos, fizeram crescer a poluição do ar (por agentes químicos ou outros, inclusive o ruído) e geraram degradação do meio ambiente e alteração da qualidade de vida das populações.

A preocupação com o risco na vida social moderna, declara Giddens (2002), não tem nada a ver com a prevalência de perigos para a vida, pois atualmente a população está melhor assistida do que em séculos anteriores. O risco, hoje, tem a ver com acontecimentos futuros que irão comprometer a qualidade de vida das pessoas e até, quem sabe, a sobrevivência do homem na Terra. A população geral está consciente dos riscos existentes, ainda que muitas vezes de maneira vaga, e hoje ninguém pode se livrar completamente dos sistemas da modernidade; essa é uma consequência de viver em um mundo de riscos.
E o ruído? Ele é invisível e seus efeitos também. A noção do que é ruído pode variar de pessoa para pessoa. Porém, o organismo tem limites físicos para suportá-lo. Ruído em excesso pode provocar surdez e desencadear outras doenças e a sua presença está diretamente relacionada à saúde mental das pessoas (HUNGRIA, 1995; SANTOS; MORATA, 1994). Ele se apresenta como um objeto de estudo interessante, pois afeta diretamente a saúde das pessoas, desqualifica o ambiente onde elas vivem e traz problemas de ordem social, na medida em que seus efeitos alteram e degradam as relações sociais.

A poluição sonora causa efeitos adversos à saúde humana, como os auditivos (perdas auditivas, zumbidos) e efeitos cumulativos ou efeitos secundários e terciários (ex: estresse, risco de hipertensão e infarto), além de efeitos socioculturais, estéticos e econômicos (ex: isolamento social, queda da qualidade acústica na vizinhança, depreciação do valor dos imóveis).

De acordo com a OMS (1980), mensurar as consequências do ruído sobre a qualidade de vida das pessoas é difícil, infelizmente, pois os fatores que interferem na análise são diversos, inclusive outros relacionados ao próprio meio ambiente. Apesar disso, a entidade afirma ser necessário estudar o ruído causado pela circulação dos veículos, já que esta situação envolve a população mundial em grande escala.

\section{A percepção e a questão ambiental}

Do ponto de vista da neurociência (LENT, 2005), percepção é a capacidade que seres humanos têm de associar as informações sensoriais à memória e à cognição, de modo a formar conceitos sobre o mundo e sobre nós mesmos e orientar nosso comportamento. Para o autor, a percepção é dependente, mas diferente dos sentidos, pois envolve processos complexos que a tornam uma experiência mental particular.

Desta maneira, depreendemos que os sentidos que se encarregam da primeira etapa da percepção são responsáveis pela parte analítica do processo e que, ao final, permitem a tomada de consciência do mundo que nos cerca, alterando comportamentos e a forma de vermos o mundo.

Se a percepção auditiva e o funcionamento do órgão auditivo são de fundamental importância, entendemos que a maneira como os sujeitos percebem o mundo, de um ponto de vista menos orgânico e mais voltado para ques- 
tões psicológicas, também o é. Segundo Del Rio (1996), a percepção é um processo mental de interação do indivíduo com o meio ambiente que se dá através de mecanismos perceptivos propriamente ditos e, principalmente, cognitivos, onde coexistem sensações (a auditiva, por exemplo) e contribuições ativas do sujeito ao processo perceptivo, desde a motivação à decisão e à conduta.

Merleau-Ponty (1999) comenta que, para efetivamente sentirmos algo, é necessário que de fato as situações existam e que um corpo próprio possa analisá-las. O corpo e suas sensações seriam o meio de comunicação entre as coisas e o mundo. Porém, não podemos ignorar que o sujeito da percepção, aquele que sente e interpreta as sensações, está impregnado por motivações próprias que interferem no processo perceptivo.

Aqui se envolve a questão de que há muitas formas de percebermos o mundo. Cada um de nós é uma lente exclusiva, fundamentada e polida por temperamento e educação. Nossas respostas à natureza e ao mundo são tão diversas quanto nossas personalidades. Podemos reagir de forma atônita, horrorizada, deslumbrada ou com indiferença àquilo que presenciamos na biosfera (SOULE, 1997).

Múltiplas percepções valorativas da natureza sempre conviveram lado a lado nas diversas culturas, nas quais o ser humano aprende que deve cuidar daquilo a que dá valor. Por questões biológicas, históricas e culturais, o ser humano é capaz de dar valor a coisas, sentimentos, espaços e lugares. É capaz de discernir entre certo e errado, ético e antiético, moral e imoral, limpo e sujo, bom e ruim. $\mathrm{O}$ ser humano valoriza porque percebe. Nessa concepção, a percepção está colocada no plano da compreensão, da emoção. Ora, não raciocinamos sem emoção e damos valor histórico, financeiro e moral para aquilo que percebemos (HEEMANN; HEEMANN, 2003).

Quando nos detemos à questão da exploração das riquezas da Terra, verificamos grande empenho da sociedade produtiva em deter ou minimizar os efeitos da exploração sobre o ar, sobre a água e o solo, haja vista que nos últimos 20 anos assiste-se à proliferação de inúmeros acordos e tratados sobre o meio ambiente (GOLDBLAT, 1996). Neste sentido, e tendo em vista a intensificação dos problemas ambientais, é que observamos a ampliação de pesquisas relacionadas à preservação e ao planejamento que buscam observar e explicar os padrões comportamentais relacionados ao homem e ao meio ambiente (KOZEL-TEIXEIRA, 2001).
Embora o estudo de percepção ainda esteja comumente situado dentro do campo da Psicologia, ele tem se desenvolvido principalmente pelas pesquisas em outros campos e disciplinas. Podemos citar como exemplos de disciplinas que vêm utilizando este tipo de estudo a Arquitetura, o Urbanismo e a Geografia. Nestes estudos, utilizam-se conceitos da Psicologia aplicados ao espaço, tanto no que se refere à percepção como ao comportamento humano. Segundo Goodey e Gold (1986), a Geografia do Comportamento e da Percepção, baseada em visões subjetivas de mundo, tem origem em pesquisas behavioristas que têm por finalidade a compreensão do comportamento humano.

Os autores explicam que até pouco tempo a Geografia, para compreender questões relacionadas ao meio ambiente, lançava mão do behaviorismo, uma visão reducionista, na qual se analisa a relação entre homem e ambiente a partir de um modelo de estímulo-resposta. Neste modelo, os processos cognitivos e a consciência das pessoas desempenhavam um papel de pequena importância para a Geografia. Para os behavioristas, as paisagens, aglomerados humanos e modos de vida eram simples manifestações de modelos e teorias científicas, nos quais valores, intuição e imaginação eram desprezados. As pessoas e os lugares eram objetos a serem estudados sem que a experiência e a vivência no dia a dia fossem consideradas.

A lacuna gerada pelas pesquisas behavioristas gerou uma insatisfação que levou à necessidade de se estudar o indivíduo como alguém que molda, ao mesmo tempo em que reage às condições do ambiente físico e social. Desta forma, com o behaviorismo a relação homem-ambiente passa a ser estudada considerando-se as verdadeiras complexidades do comportamento humano, em especial o fato de que as ações do homem no meio em que ele vive são mediadas por processos cognitivos. Nesse sentido, pesquisas na Geografia do Comportamento e da Percepção ganham força e atingem questões de caráter moral, social e de planejamento urbano, salientando laços entre percepção, tomada de decisões e comportamento. São exemplos os estudos sobre mercado imobiliário, mobilidade, imagens urbanas, design urbano e educação ambiental (GOODEY; GOLD, 1986).

Podemos então argumentar que, atualmente, estuda-se a percepção em uma tentativa de explicar observações realizadas sobre o mundo que nos cerca e tal tarefa não é mais prerrogativa dos geógrafos. A interdisciplinaridade tem marcado pesquisas que estudam o ambiente e as relações estabelecidas pelo homem. Apesar da diversidade de abordagens, os pesquisadores da percepção ambiental (grupo 
com o qual se identificou a autora dessa pesquisa) buscam o entendimento dos processos pelos quais as pessoas atribuem significados ao meio ambiente, voltando-se principalmente às decisões políticas, relacionadas ao planejamento ambiental e urbano, e, ao incorporar o conhecimento espacial, estes pesquisadores passam a analisar o comportamento dos indivíduos inseridos em sistemas de valores (KOZEL-TEIXEIRA, 2001).

Del Rio e Oliveira (1996) conceituam a percepção em uma abordagem ampla. Os autores, baseando-se em Piaget, acreditam que a Psicologia situaria as preocupações dentro de um processo mental (cognição) mediante o qual, a partir de interesse e de necessidade, estruturamos e organizamos nossa interface com a realidade e o mundo. A partir desta seleção do que é ou não importante, pode-se assim dizer, os sujeitos escolhem as informações percebidas, armazenando-as na memória e conferindo-lhes significado.

Segundo Kaplan, Sadock e Greeb (1997), pesquisadores da área da saúde mental, o insight é de grande relevância quando o tema é a percepção. Esta palavra, de origem americana, muito utilizada nos meios médico e psicológico, "refere-se à introvisão, autoentendimento, compreensão de si mesmo, capacidade que uma pessoa tem para entender a origem, a natureza, os mecanismos e o significado de seu comportamento, sentimentos e atitudes" (OSOL, s.d., p. 570).

\section{Insight emocional ou intelectual: qual deles contribui para a verdadeira percepção $e$ valorização do ruído?}

Partindo desta definição, Kaplan, Sadock e Greeb (1997) explicam que a percepção é construída, também, por meio da capacidade de julgamento e de insights de uma pessoa. Para os autores, o insight se dá na medida em que duas fases são completadas e somente a partir disso é que a percepção efetivamente acontece. O processo de percepção tem início com o insight intelectual, que está presente quando o indivíduo reconhece situações ou fatos e interioriza conhecimento sobre eles. Existe uma limitação no insight intelectual e pessoas que não passam dele se tornam incapazes de aplicar o conhecimento adquirido para alterar experiências futuras. Complementando o insight intelectual, existe o insight emocional, que está presente quando a conscientização da pessoa sobre determinado fato, isto é, o conhecimento, promove a alteração básica de comportamento. Desta forma, o indivíduo muda alguma coisa na medida em que ele altera padrões comportamentais, por meio do conhecimento adquirido a partir de sensações e da conscientização deste conhecimento.

Está clara a importante relação entre o perceber e o sentir, tanto que Del Rio (1996) afirma que a percepção é um processo mental de interação do indivíduo com o meio ambiente, e esta se processa a partir de mecanismos perceptivos propriamente ditos e, principalmente, cognitivos. Porém, apesar da percepção ser um processo mental individual, percepções comuns a uma coletividade também podem ser observadas. Portanto, cabe ressaltar, buscando Del Rio e Oliveira (1996), que o estudo dos processos mentais relativos à percepção ambiental é fundamental para se compreender melhor as inter-relações entre o homem e o meio ambiente. É necessário levantar as expectativas de uma comunidade para que as ações sobre o meio, que afetarão a qualidade de vida de várias gerações, sejam pensadas, gerando satisfação psicológica com o ambiente.

É nesse contexto que entendemos ser a percepção ambiental de grande valor para pesquisas que tenham por finalidade estudar a relação existente entre o homem, a sociedade e a natureza. A percepção ambiental - que tem suas raízes nos trabalhos de White (apud ZANELLA, 2006) - não se preocupa, especificamente, com concepções a priori, assumindo apenas, sem os exageros do determinismo, as dependências recíprocas entre fatos humanos e fenômenos do ambiente físico natural, sendo interdisciplinar em sua visão.

A autora, baseada principalmente nos trabalhos de White, comenta que a percepção ambiental tem procurado compreender os processos geográficos, relacionados a eventos naturais, e as respostas humanas a estes eventos; considera a experiência ambiental do indivíduo como influenciadora de suas percepções de mundo real e de seus comportamentos e, por fim, tem procurado possíveis soluções em benefício da sociedade, contribuindo para a política de planejamento.

Para Foin (1976, p. 95), "percepção ambiental é um processo através do qual os indivíduos interpretam e reagem aos seus ambientes e às trocas ambientais". Estas percepções podem ou não sofrer variações, por exemplo, em virtude de condições socioeconômicas e culturais diferenciadas.

Embora as percepções sejam "subjetivas para cada indivíduo, admite-se que existam recorrências comuns, seja em relação às percepções e imagens, seja em relação às condutas possíveis" (Del Rio, 1996, p. 4). 
Além disso, ao estudar-se a percepção, não se pode deixar de lado aqueles que veem o problema de fora como, por exemplo, os planejadores ou gestores nos diferentes níveis, pois, como afirma White (1974), a tomada de decisão está comumente ligada à política administrativa.

\section{Mundo vivido e topofilia: como o ruído interfere na relação da pessoa com o local em que vive}

Segundo Zanella (2006), dois conceitos são importantes para aquele que estuda a percepção considerando a relação homem-ambiente: mundo vivido e topofilia. Como a investigação é complexa, por estar ligada ao entendimento da conduta humana, torna-se necessário, além dos instrumentos de análise cognitivos comportamentais, buscar subsídios na fenomenologia, no idealismo e no existencialismo.

Para a autora, a noção de "mundo vivido" na Geografia focaliza-se nos indivíduos e na experiência social, com a sua interação construída sobre as relações interpessoais. Assim, os pesquisadores desta ciência entendem o meio, tanto físico quanto cultural, como elemento ativo na formação de experiências.

Somente uma leitura interiorizada do vivido humano pode nos permitir compreender os homens e consequentemente a sua organização espacial. O objetivo central dessa abordagem é o ser humano, tendo em vista a compreensão da estrutura e dos significados do espaço vivido, sobretudo porque os seus trajetos pela Terra significam vida (KOZEL-TEIXEIRA, 2001).

O conceito de "mundo vivido" é proveniente da fenomenologia, estudado inicialmente por Husserl, que o definiu como um conjunto de coisas, valores, bens e mitos inerentes a um mundo subjetivo. Este mundo seria onde nos colocamos frente a experiências diversas e onde, por meio da reflexão, o sentido e a transcendência do próprio mundo se explicam. A cultura é considerada como portadora de sentido e geradora de significados e o mundo é construído na troca de significações, intermediadas por mensagens que resultam no ser social (KOZEL-TEIXEIRA, 2001).

Zanella (2006) comenta, em seu estudo sobre a percepção, que o mundo vivido poderia ser considerado como o substrato latente da experiência. Ao se falar de experiência individual ou coletiva, os padrões visíveis de movimento e a atitude consciente podem ser elucidados pela exploração do dinamismo das tensões de suas bases subjacentes. Para a autora, o mundo vivido geográfico, descrito por Darle em
1952, mostra-se como sendo o mundo experienciado como cenário (tanto o natural como o construído) pelo homem e como ambiente que provê sustento e uma moldura para a existência. Assim, a partir deste mundo vivido, cria-se uma aparente simpatia ou, então, vivenciam-se experiências felizes no mesmo.

Há que se considerar, ainda, nesta rede de interpretações, os elos afetivos que os sujeitos desenvolvem com o meio em que vivem. Topofilia, termo utilizado para definir este elo, seria a relação do homem com o meio ambiente, incluindo aí as experiências mais agradáveis das paisagens e dos lugares. De acordo com Tuan (1980), topofilia "é o elo afetivo entre a pessoa e o lugar ou ambiente físico" (p. 5). Segundo o referido autor, "o meio ambiente pode não ser a causa direta da topofilia, mas fornece o estímulo sensorial que, ao agir como imagem percebida, dá forma às nossas alegrias e ideais" (p. 129).

Tendo por base esses conceitos de mundo vivido e topofilia é que procuramos entender, se possível, o comportamento e as atitudes dos moradores dos Setores Estruturais Especiais de Curitiba (SEE), onde o ruído urbano é intenso, baseando-nos na crença - e em concordância com Tuan (1980) - de que o indivíduo investe parte de sua vida emocional no seu lar e nas imediações onde mora.

Ainda segundo o autor, o mundo que escolhemos para viver - normalmente nossa casa e nosso bairro - está fundamentado em um passado e remete ao futuro, trata-se da soma de experiências vividas e compartilhadas, que nem sempre geram reflexão. Na vida diária não se reflete, diz Buttimer (1982), não se examina criticamente sobre os horizontes do cotidiano, e esta afirmativa pode explicar por que o ruído urbano não é devidamente valorizado em nossa sociedade.

Buttimer (1982) comenta que a relação entre o homem e o meio sempre foi objeto de estudos que têm por finalidade, em algumas ciências (Geografia Humanística, por exemplo), questionar o espaço, levando em conta os valores criados pelo homem. Segundo o autor, as experiências geográficas revelam o mundo vivido, conduzem à compreensão do lugar e à apreensão do espaço, instrumentos importantes para a conscientização das pessoas acerca das questões ambientais que as cercam, inclusive o ruído.

Nossa casa está permeada de valores, lembranças e eventos que a tornam um lugar especial. Segundo Schmid (2005, p. 13), "a casa acolhe, ela atende a um conjunto de necessidades básicas de segurança, envolvimento [...] é como se oferecesse consolo interminável ao ser humano [...]", 
e o mundo excita e, muitas vezes, se mostra desconfortável, o antônimo da casa.

Na realidade, parece haver uma dicotomia entre a casa e o mundo. O mundo excita, enquanto que a casa acolhe, conforta. Para o autor, o mundo, lugar público, onde muitos se encontram, é muitas vezes sinônimo de espaço desconfortável, enquanto que na casa a qualidade mais importante parece ser o conforto.

Exatamente porque a noção de espaço não é atemporal há mudanças na noção de conforto e na relação entre este e a residência das pessoas. Houve épocas em que a casa, designada por alguns como máquina de morar, era desconfortável e impessoal (SCHMID, 2005), deixou de ter um lugar expressivo na vida das pessoas para tornar-se utilitária, um ambiente geometricamente asséptico.

Porém, parece-nos que a noção de casa está mais diretamente relacionada com a proposta de Tuan (1980), que diz ser o lugar escolhido como local de moradia por alguém, normalmente um invólucro de familiaridade que protege o ser humano das perplexidades do mundo exterior.

Desta forma, confirmando o dito por Heemann e Heemann (2003), conforto é um conjunto de valores. É importante estarmos bem abrigados durante o inverno (contexto ambiental) para não passarmos frio; relaxados no fim do dia ou nas férias (contexto sociocultural); sentir-se bem ou especial para alguém (contexto psicoespiritual).

Podemos inferir, portanto, que um ambiente confortável perpassa por certo nível de realização de conforto em um determinado contexto. Quando muitas pessoas estão juntas, em um ambiente despojado e público, é natural que se espere ser este um ambiente desconfortável, principalmente do ponto de vista sonoro.

Aqui entra a noção de conforto acústico. A acústica é o aspecto de maior complexidade do ambiente construído (SCHMID, 2005) - pois os ouvidos são muito sensíveis e, muitas vezes, pelo excesso de capacidade de percepção, inviabiliza a realização de tarefas muito necessárias ao organismo humano, como dormir e descansar.

Se a casa tem uma conotação de acolhimento, devemos supor que é o ambiente destinado ao relaxamento, à troca de emoções e, portanto, deve ser confortável do ponto de vista acústico. Para dormir precisamos de silêncio e constância. Quem repousa quer ausência de tensão, porém se a pessoa escuta uma música, por escolha própria, está sujeita à tensão. Acostumamo-nos ao barulho dos carros, porém, freadas violentas nos despertam e interrompem ciclos de descanso.
Segundo Lent (2005), acomodação e constância são aspectos importantes da percepção. Acostumamo-nos a um determinado som porque ele é constante. Por exemplo, o tic-tac de um relógio. O barulho é constante; desta forma, nos acostumamos a ele e dormimos sem sobressalto. O barulho da chuva é constante, porém trovões não são, e podemos acordar com eles. O movimento do tráfego é constante, mas as freadas bruscas ou uma buzina não são, tendemos a buscar a fonte sonora, sobressaltados. Para o autor, o sentido da audição estabelece "posições hierárquicas" para cada som e o cérebro humano analisa e reage aos estímulos, como que dissecando seus matizes. E mais, o córtex possui função integradora e sintética; desta forma, associa sons a fatos experimentados anteriormente e, mesmo em repouso, reagimos ao mundo sonoro.

Nesta linha de raciocínio, o cérebro estabelece uma hierarquia de modo a que cada estímulo seja interpretado com base em experiências vividas, o que faz com que, em muitas situações, as pessoas se acostumem com certa estimulação e não desenvolvam atitudes de repulsa ou de proteção.

Resumindo, o ambiente sonoro em que vivemos requer adequação à atividade realizada. Porém, não é raro nos ambientes construídos, principalmente em residências onde a função básica é o abrigo, observarmos dificuldades de acústica relacionadas ao uso inadequado de materiais de construção ou mesmo localização do imóvel.

$O$ fato é que o som no ambiente incorpora traços deste, torna-se também uma realidade e, na maioria das vezes, altera a qualidade de vida das pessoas que ali habitam. Segundo Giddens (2002), a sociedade moderna caracteriza-se pelo ceticismo generalizado, acreditando que os riscos e perigos atuais se devem ao contexto social em que vivemos e nada pode ser feito em relação a isso.

\section{Investigando o ruído ambiental e seus efeitos sobre os moradores dos SEE de Curitiba}

Para atingirmos o objetivo desta pesquisa, foram analisadas as respostas de 100 moradores dos SEE de Curitiba (Figura 1) sobre a presença da poluição sonora em seus lares e seus efeitos sobre sua qualidade de vida. Dos 100 entrevistados selecionamos alguns depoimentos que deixaram evidente a interferência ou não do ruído sobre a relação topofílica do respondente. 


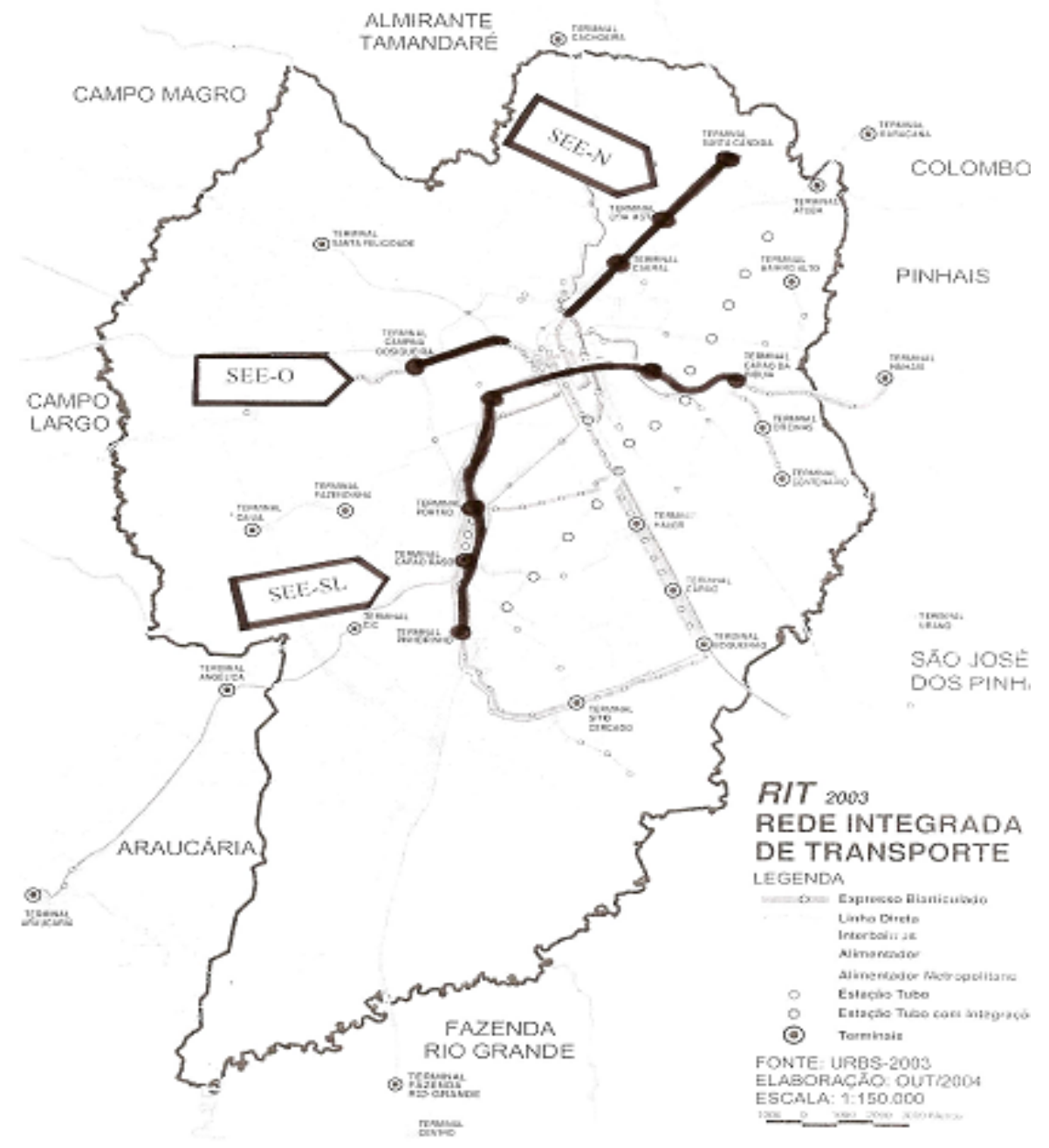

FIGURA 1 - SETORES ESPECIAIS ESTRUTURAIS DE CURITIBA

FONTE: IPPUC, 2006

A amostra foi selecionada a partir da delimitação do número de quadras existentes em cada um dos setores estruturais. Em seguida, por meio de sorteio realizado com o auxílio do programa MATLAB, elegemos 100 quadras e depois os 100 pontos em que foram coletados os dados da pesquisa empírica. Este procedimento considerou a proporcionalidade de cada quadra. No SEE-O foram sorteados 11 pontos, no SEE-N foram sorteados 27 pontos e no SEE-SL foram sorteados 62 pontos.
Em seguida, utilizamos o mesmo programa para o sorteio da residência onde foi aplicado o questionário. Quando não foi possível aplicar o protocolo na residência sorteada, escolhemos a seguinte na numeração da rua.

O questionário (RIBAS, 2007) foi administrado em interação pessoal, ou seja, entrevista individual. Optamos por esta metodologia pela vantagem de permitir acesso a informações ricas em detalhes. Foram analisados os seguintes aspectos: Se o respondente aponta, espontaneamente, o 
ruído como fator ambiental negativo; Como o respondente avalia a presença do ruído em sua residência; Como o respondente avalia o conforto acústico em sua residência; Qual a relação topofílica que o respondente possui com o local onde reside e se a presença do ruído interfere nesta relação.

Tanto os questionários quanto a medição de ruído foram aplicados no interior das residências selecionadas.

A caracterização da amostra foi realizada por meio do programa SPHINX LEXICA. Os dados objetivos foram digitados em planilha eletrônica e posteriormente tratados estatisticamente. Os dados sobre a percepção foram anali- sados de maneira quantitativa e qualitativa e discutidos à luz das referências literárias estudadas.

Segundo Ribas (2007), nos SEE o ruído urbano é intenso e invade as residências em seu entorno, provocando reações diversas nos moradores da região. A autora, ao medir o ruído no interior das residências (Gráficos 1,2 e 3), verificou que dos 100 pontos onde ocorreram as medições $86 \%$ possuem níveis de pressão sonora que extrapolam os valores mínimos estipulados por diferentes normas (ABNT - NBR 10151 e NBR 10152 e Lei 10.625 de CURITIBA, Resolução 001 do CONAMA). Resta-nos verificar como a

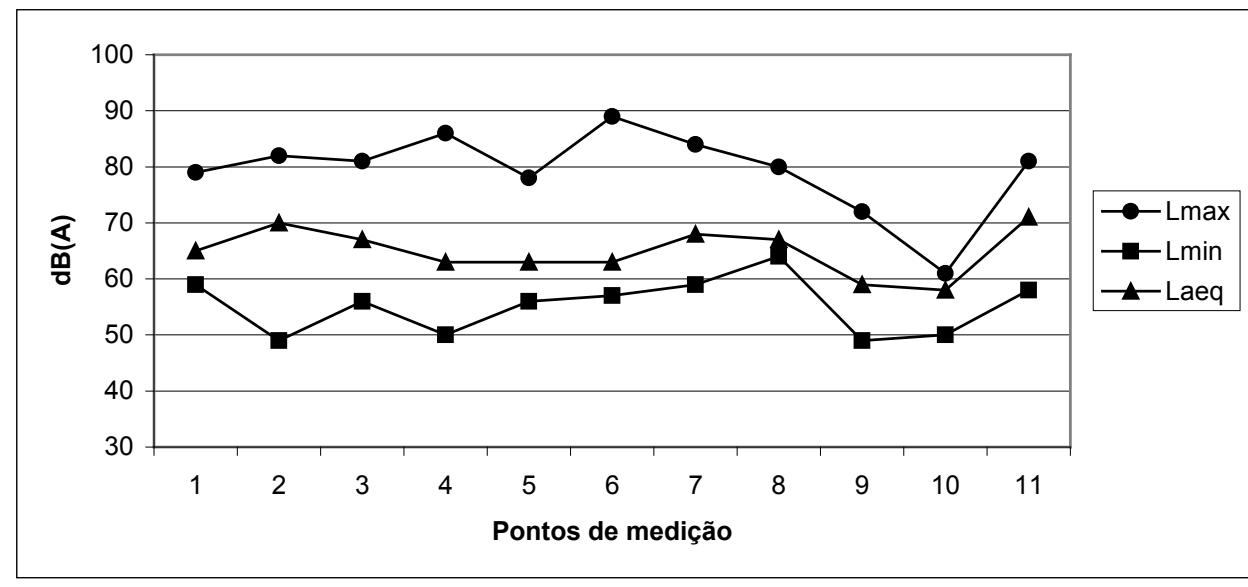

GRÁFICO 1 - SEE OESTE.

Lmax $=$ nível máximo $;$ Lmin $=$ nível mínimo $;$ Laeq $=$ média equivalente de ruído

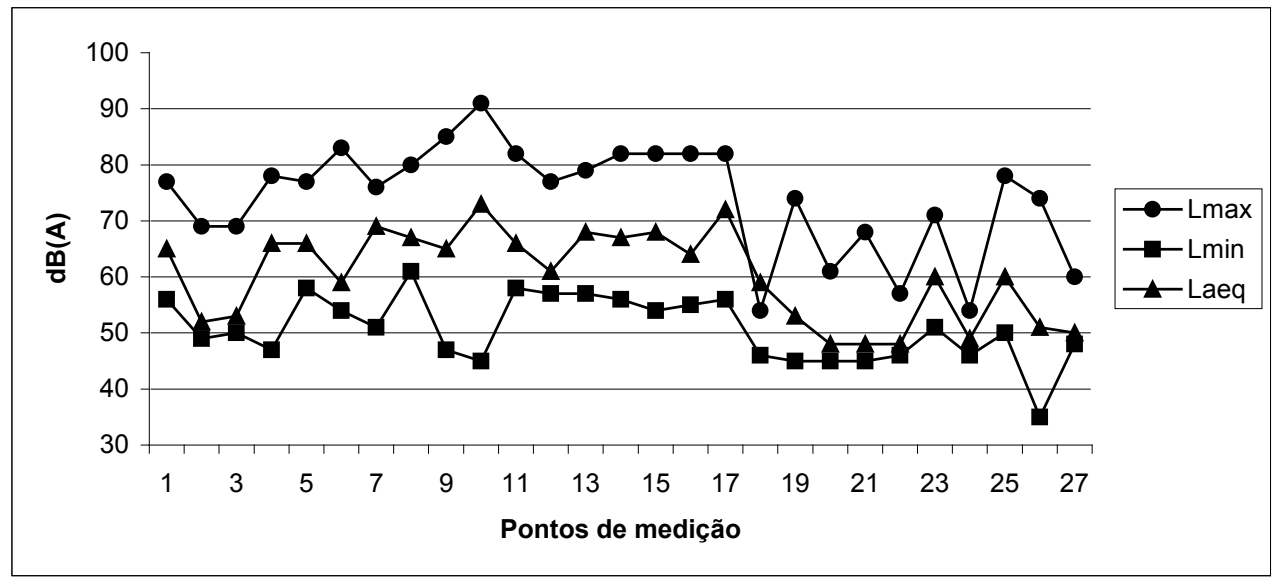

GRÁFICO 2 - SEE NORTE.

Lmax $=$ nível máximo $;$ Lmin $=$ nível mínimo $;$ Laeq $=$ média equivalente de ruído 


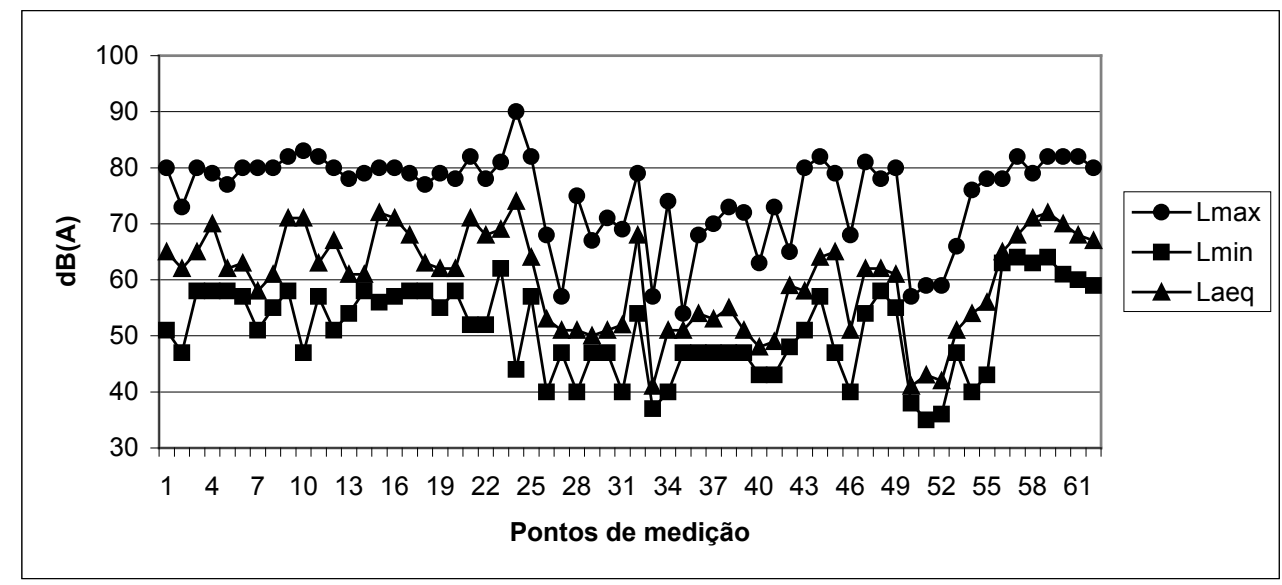

GRÁFICO 3 - SEE SUL LESTE.

Lmax = nível máximo; Lmin = nível mínimo; Laeq = média equivalente de ruído

população reage a este fenômeno que, atualmente, é marca registrada dos centros urbanos.

Dos 100 indivíduos entrevistados, 71\% são do sexo feminino e $29 \%$ do sexo masculino. A idade mínima registrada foi de 24 anos e a máxima de 71 anos. A idade média constatada foi de 32,98 anos. A maioria da amostra desta pesquisa (56\%) tem formação escolar em nível de $1 .^{\circ}$ grau e apenas $5 \%$ não possuem escolaridade.

Com relação à ocupação, $20 \%$ da amostra não trabalham - ou por serem do lar, estudantes ou aposentados. Os demais se distribuem em diferentes categorias ocupacionais, seja no mercado de trabalho formal ou informal.

Observamos na amostra estudada que a maioria dos respondentes $(70 \%)$ recebe, mensalmente, valores inferiores a R\$2.100,00. Utilizamos como referência o valor do salário mínimo vigente na época das entrevistas, isto é, $\mathrm{R} \$ 350,00$.

De acordo com o resultado das entrevistas realizadas junto aos moradores dos SEE de Curitiba, observou-se que, de um modo geral, as percepções sobre esta questão foram bastante constantes, especialmente no que tange ao ruído, pois $89 \%$ dos entrevistados, espontaneamente, apontaram-no como o fator mais negativo e mais frequentemente presente nas suas residências. Quando sensibilizada, 100\% da amostra apontou o ruído como fator negativo. Porém, na maioria dos casos o ruído não interferiu negativamente sobre a relação topofílica do respondente, conforme veremos nos depoimentos relatados a seguir.

\section{Mecanismos cognitivos, sensações e percepç̃̃es acerca do ruído}

Giddens (2002) afirma que o estilo de vida refere-se a práticas rotinizadas incorporadas em hábitos de vestir, comer, agir e se relacionar. O autor coloca que, nas condições da alta modernidade, a escolha de um estilo de vida, muitas vezes, não é uma escolha, mas uma imposição, na medida em que um indivíduo abraça tal estilo não somente porque essa prática preenche necessidades utilitárias, mas porque dá forma material a uma narrativa de autoidentidade.

Cada pequena decisão tomada por uma pessoa no seu dia a dia contribui, portanto, para a formação de uma identidade e a escolha de uma residência, de um bairro ou determinada região da cidade para fins de moradia perpassa por estas questões.

No caso da comunidade entrevistada, tal atitude ficou evidenciada em alguns depoimentos, onde a escolha do local em que moram se deu por fatores extemporâneos relacionados à situação socioeconômica e de status do respondente.

Eu adoro este bairro, o nome mesmo é Bigorrilho, mas chamam de Champagnat, pois é mais chique. Tem de tudo por aqui... mercado, farmácia, academia, e o acesso de carro não é difícil. É diferente, muito melhor que outras regiões da cidade, basta andar um pouco que a gente nota a grande diferença... (Gilda, 45 anos, ponto 5). 
Moro aqui há 20 anos, desde que casei. Este foi o primeiro prédio da região. Antes era tudo muito simples, hoje não, tem prédios bonitos, altos. Mora aqui gente que tem condições financeiras boas. Isto favorece que o lugar seja de boa qualidade, gente mais educada (Julia, 53 anos, ponto 7).

Eu vim de Santa Catarina há 4 anos. Precisava de um lugar perto da faculdade e perto de boas escolas. Escolhi aqui (Sandra Mara, 34 anos, ponto 22).

A maioria da amostra estudada (61\%) está fixada há mais de três anos no local onde foram coletados os dados desta pesquisa. Também observamos que a maioria da amostra (86\%) permanece em casa por mais de 8 horas todos os dias. Podemos inferir que é neste espaço e neste tempo determinado que a história destas pessoas acontece, tanto do ponto de vista individualizado como do ponto de vista comunitário.

Para Giddens (2002), todas as culturas têm que lidar com o tempo e com a forma de situar-se espacialmente. Não há sociedade que não tenha o sentido de futuro, presente e passado e marcadores espaciais são utilizados para isso. Segundo o autor, a modernidade está marcada pela separação entre tempo e espaço, o que dificulta, muitas vezes, a formação de uma identidade, onde o "quando" está diretamente conectado ao "onde", sem necessariamente passar por um determinado lugar. Porém, o que vemos é a busca pela identidade individual, que se converte em questões de personalidade para alcançar determinados significados, que serão convertidos em identidade social.

Vale ressaltar também que, conforme já explicamos, os níveis de ruído no interior da maioria das residências extrapolam os índices recomendados legalmente e tal fato pode ser o gerador desta opinião na amostra, já que, segundo Del Rio (1996), a percepção se dá por meio de mecanismos cognitivos, onde coexistem sensações e contribuições ativas do sujeito ao processo.

Porém, verificamos que, apesar da percepção do ruído ser semelhante, a maneira como as pessoas valorizam o ruído é distinta:

Eu moro aqui há 12 anos, e hoje uma das coisas que mais me incomodam é o barulho. É irritante. Tem ônibus, caminhão, carro passando o tempo todo... Tem horas do dia que não consigo nem ver televisão ou me concentrar na leitura (Sandra, 70 anos, ponto 6).
Eu adoro morar aqui, mas se tem uma coisa que incomoda é o barulho. Todo dia, o dia inteiro tem barulho, à noite é pior. Mas é até gostoso, pois mostra que estamos vivendo num local agitado, moderno (Josiane, 24 anos, ponto 94$)$.

Tem três coisas ruins aqui, o barulho, o trânsito e a distância das coisas. Cada vez que preciso de pão ou remédio tenho que andar muito. Tem ônibus na porta, mas não dá para pagar sempre. E o barulho incomoda, as crianças têm dificuldades para estudar em alguns horários por causa do barulho (Joana, 32, ponto 34).

Pontos negativos... eu acho que o barulho é um deles. Eu moro aqui há pouco tempo. Antes eu morava no centro, por isso acho que aqui é mais tranquilo, apesar de ter barulho, principalmente no final da tarde (João Carlos, 32 , ponto 36 ).

Segundo Heemann e Heemann (2003), múltiplas valorações da natureza sempre conviveram lado a lado nas comunidades em função do contexto sociocultural e da história das pessoas. Estas diferenças acabam por influenciar o valor que damos aos fatos, inclusive aqueles que se configuram um problema.

Para Goldblat (1996), a percepção de um problema dependerá das expectativas culturalmente variáveis a respeito daquilo que se constitui como negativo e muitos valores já estão impregnados na sociedade. As citações acima ilustram esta prerrogativa.

Além da homogeneidade das respostas, observamos que a percepção do ruído suplantou a percepção de outros problemas socioambientais. Os entrevistados identificam o ruído como fator negativo em maior grau que o problema gerado pelo intenso tráfego de veículos, a segurança e a violência, fatores que marcam as grandes cidades atualmente.

Este resultado, surpreendentemente, difere de outras pesquisas que avaliaram a percepção da poluição sonora em Curitiba (LACERDA; RIBAS; MARQUES; MENDES, 2004; OLIVEIRA, MOCELIN; RIBAS, 2005) e que apontaram para o fato do ruído urbano não ser percebido e valorizado como um fator de risco pelos entrevistados. Nestas pesquisas, dentre os problemas levantados pelos entrevistados estavam a segurança pública e a violência, e o ruído, quando citado, aparecia entre os últimos.

Isto pode ser explicado pelo fato de que, com o passar do tempo, o ser humano aprende a dar valor às coisas e, em 
função disso, as percepções pessoais se modificam, principalmente quando se vive em uma comunidade permeada por informações.

Segundo Giddens (2002), a produção de informações sobre um determinado risco pode gerar em comunidades leigas uma refletividade rotineira, o que acarretaria a mudança de comportamento de certo grupo de pessoas sobre um determinado assunto.

Podemos inferir que, nesta pesquisa, o ruído foi relacionado preferencialmente como um fator negativo em detrimento dos demais por estarmos pesquisando uma população que habita em regiões qualificadas da cidade de Curitiba. As áreas onde se localizam os SEE de Curitiba são, atualmente, os locais de maior investimento urbano da cidade, nos quais se incrementa a cada dia a oferta por serviços, a oferta de equipamentos voltados para a saúde e para a educação e há grande disponibilidade de transporte coletivo. Nas ruas dos SEE, próximas ao centro da cidade, é visível a aglomeração de edifícios destinados às classes mais abastadas. A qualidade socioambiental da região é boa.

Se espontaneamente $89 \%$ da amostra identificaram o ruído como um dos aspectos negativos presentes na região em que habitam, quando os respondentes foram sensibilizados para o tema desta pesquisa o índice subiu para $100 \%$, ou seja, todos os entrevistados afirmaram que percebem o ruído e que este interfere, de alguma maneira, na sua qualidade de vida.

Apesar de identificarem a presença do ruído urbano na região em que moram, observamos novamente que as pessoas entrevistadas se referem a ele de maneiras distintas. Alguns entrevistados demonstraram aversão e outros, apesar de o identificarem como algo nocivo, nem tanto. Vejamos:

É muito ruim, não durmo, não me concentro... quando quero usar o telefone tenho que ir para o banheiro. $\mathrm{Meu}$ marido até briga comigo (Juliana, 43 anos, ponto 24).

Eu gosto de ambientes agitados. Vou sempre a barzinhos e festas, onde tem muito barulho, mas aqui em casa a coisa é ruim. Quando preciso descansar gosto de ter um ambiente tranquilo, e aqui é difícil. Decididamente, o ruído me incomoda, principalmente quando quero descansar (Lucas, 27 anos, ponto 11).

Sou professora de educação física e estou acostumada com barulho, mas o problema é que à noite as freadas e buzinas são atordoantes. Me acordam o tempo todo. Fico sobressaltada e irritada (Lílian, 32 anos, ponto 1).

Eu acho barulho aqui em casa normal. Tem barulho, mas não é muito forte, a gente se acostuma. Preferia morar num local menos barulhento, mas aqui é muito prático, tem tudo por perto, e isto facilita minha vida, portanto, não acho o barulho muito ruim (Maria José, 56 anos, ponto 61 ).

A percepção auditiva depende de experiências objetivas e subjetivas do indivíduo exposto ao ruído, depende das experiências vividas, do local em que se dá a propagação e, também, do modo de vida das pessoas. Neste sentido, podemos esperar que o ruído cause percepção ruim em uma pessoa e em outra não. Um concerto de rock é agradável para algumas pessoas e para outras não. Identificamos dois depoimentos interessantes que traduzem esta percepção.

Eu moro aqui há anos, mais de 15. Estou acostumada com o barulho da rua. Há um ano meu marido comprou um sítio em Quatro Barras. Achei ótimo, pois agora que estou aposentada posso ir para lá no final de semana e descansar. Que nada, não consigo dormir, pois o barulho dos grilos é insuportável. Eles não me deixam descansar, e de manhã tem passarinho e pato (Izaura, 58 anos, ponto 55).

Você pergunta qual barulho me incomoda mais... acho que o das crianças, pois o barulho da rua é só trancar a porta e janelas, mas as crianças... eles adoram música alta, ficam no quarto ouvindo música num volume muito alto, acho até que vão ter problemas de audição. Eu também gosto de música, mas aquelas tranquilas, que dá para dançar (Julia, 42 anos, ponto 83).

Com estas duas colocações, podemos verificar que qualquer tipo de som pode ser encarado como ruído, dependendo apenas da situação que envolve aquela pessoa que escuta. E a percepção, neste caso, leva em conta não somente a sensação física do som, mas todo o contexto que envolve uma determinada situação auditiva. Merleau-Ponty (1999) explica que o sujeito da percepção está impregnado de motivações que interferem no processo perceptivo e, por isso, o que é bom para um pode não sê-lo para outro. 
Concluímos, portanto, que as pessoas têm interesses diferenciados e intenções diferenciadas, o que gera percepções diferentes sobre o mundo, inclusive sobre o ruído.

A configuração dos SEE de Curitiba favorece a propagação do ruído: todas as vias são asfaltadas; o sistema trinário de organização das vias favorece que os veículos desenvolvam altas velocidades; há grande concentração de edifícios, o que produz um efeito de "caixa" que favorece a propagação do som; o adensamento populacional é um dos maiores da cidade, o que aumenta a demanda por transporte coletivo e individual; há pouca arborização; alguns pontos dos SEE são cortados por linha férrea (RIBAS, 2007). Todos estes aspectos contribuem, portanto, para que o ruído urbano produzido nos SEE seja intenso e a população destas regiões, conforme denotam os resultados da nossa pesquisa, estão percebendo este fato.

Quando chego em casa à noite o que mais quero é descansar um pouco, relaxar, pois meu trabalho é extenuante. Ligo a TV e tento assistir ao jornal. Tento, pois o barulho é tão grande que fica difícil. Como você viu, moro numa esquina, com ônibus e carros passando dos dois lados. Tenho que fechar todas as janelas, e mesmo assim fica difícil (João, 45 anos, ponto 9).

Eu acho que tem barulho sim, mas é um barulho bem característico da região. Parece que só tem aqui. Quando vou à casa de amigos vejo com o barulho é diferente. Quando vou para a casa de meus parentes, no interior, Jacarezinho, fica mais notável ainda (Lucas, 27, ponto 11).

Neste contexto, podemos afirmar que o som produzido pelo tráfego de veículos parece marcar a paisagem sonora dos SEE de Curitiba e tal fato fica evidenciado pelos respondentes, que o apontaram como um sinal importante presente na região onde moram.

A literatura pesquisada (MAY, 1978; OMS, 1980) informa que o ruído pode causar diferentes efeitos nas pessoas. Considerando o fato de que o ruído nos SEE está acima dos valores recomendados, é de se esperar que a população pesquisada faça referência a problemas de saúde e à qualidade de vida. O questionário aplicado permitiu verificar que $95 \%$ dos sujeitos estiveram em consulta médica no último ano, sendo que $31 \%$ da amostra procuraram o médico há menos de um mês, porém nenhum dos respondentes relacionou o problema à presença do ruído.
Sabemos que sintomas causados pelo ruído têm ocorrência multifatorial; portanto, para relacionar as queixas apresentadas pelas pessoas entrevistadas em relação ao ruído urbano, fizemos algumas análises baseados em algumas respostas, onde foi possível observar claramente a marca do ruído impressionando a saúde dos entrevistados.

[...] sempre morei aqui, mas depois que eles fizeram as canaletas do expresso fiquei doente. Vou ao posto de saúde toda semana, por causa da depressão. É que o barulho me incomoda, por dentro e por fora, tem um zumbido o tempo todo na minha cabeça. Às vezes mistura o barulho dos ônibus com o da minha cabeça, é horrível (Maria, 68 anos, ponto 17).

Como eu já disse antes, o barulho é muito forte, mas o que mais incomoda são as freadas. $O$ pessoal vem fazer "pega" aqui na esquina, pois só tem um sinaleiro bem lá embaixo. Eles ficam cantando pneu e arrancando. Faz um barulho muito forte, e eu acordo várias vezes durante a noite. Já cansei de chamar a polícia, eles até veem, mas nunca pegam ninguém (Sidonie, 58 anos, ponto 38).

O som aqui é insuportável. Eu morava em Morretes, era muito tranquilo. Hoje já pareço mais acostumada, mas me sinto mais cansada e irritada do que antes, e estressada também (Ana, 56 anos, ponto 69).

Tem momentos do dia em que o ruído é irritante, fico cansada, tem alguma coisa incomodando, e quando percebo é o barulho (Ana Clara, 37 anos, ponto 87).

Estresse, cansaço, irritabilidade e dificuldades para dormir são sinais citados pelos respondentes que, facilmente, em situações específicas de escuta, podem ser relacionados com o ruído. Estes sinais podem ser explicados pelo fato de o indivíduo não conseguir relaxar, pois a exposição ao barulho constante, acima de $70 \mathrm{~dB}(\mathrm{~A})$, provoca secreção de catecolaminas e hormônios corticosteróides (OMS, 1980). Nas medições realizadas por Ribas (2007), o Laeq do ruído medido esteve acima de $60 \mathrm{~dB}$ em $51 \%$ das medições realizadas.

Para dormir bem, o indivíduo precisa de um ambiente confortável e de estímulos constantes. Observamos que 38 pessoas se referem a dificuldades para dormir. De acordo com a OMS (1980), sons bruscos e intermitentes afetam a 
qualidade do sono na medida em despertam a pessoa sem que tenha havido o repouso necessário.

Aqui tem muito barulho, mas durante o dia não me incomoda. $\mathrm{O}$ complicado é à noite, quando meu marido chega, pois ele reclama que não entende o que eu digo, e eu reclamo dele. Já brigamos por isso... (Joana, 32 anos, ponto 34).

Eu não escuto muito bem, trabalhei muitos anos numa serralheria e perdi a audição. É difícil ouvir rádio e TV, pois preciso deixar o volume alto, e daí minha mulher reclama. Se deixar num tom normal eu não escuto, e o barulho incomoda, pois dificulta ainda mais o entendimento das coisas (José Pedro, 61 anos, ponto 79).

É difícil se concentrar nas coisas com barulho. Eu preciso de silêncio para estudar, e tem horários do dia - hora do almoço e fim da tarde - que ficam impraticáveis (Lílian, 32 anos, ponto 1).

É importante referir que o ser humano é excepcionalmente adaptável (TUAN, 1980) e que os conceitos sobre o que é bom ou ruim mudam, na medida em que se aprende a viver em determinado mundo. Podemos, portanto, nos acostumar a viver em ambientes barulhentos e não associar os efeitos maléficos do ruído a problemas de saúde e, consequentemente, à qualidade de vida?

A população exposta ao ruído urbano, apesar de ciente da sua presença, não possui consciência dos efeitos que ele pode causar, o que prejudica a tomada de iniciativas com vistas à minimização destes efeitos. Tal consideração nos leva ao encontro do que autores comentaram (HEEMANN; HEMMANN, 2003; GOLDBLAT, 1996) sobre a percepção de efeitos ecológicos pela comunidade depender das expectativas criadas sobre estes efeitos. Ora, se não se cria expectativa em relação a um determinado evento, dificilmente ele será valorizado como algo importante.

Floriani (2004) diz que os problemas ecológicos somente se convertem em objeto de preocupação quando impõem um dano significativo aos seres humanos e à natureza. O ruído não causa danos à natureza em si, porém degrada o ambiente, dificultando a realização de uma série de tarefas e atividades.

Sabendo que o ruído afeta as atividades laborais, de lazer e escolares, alterando diretamente a qualidade de vida das pessoas, perguntamos aos entrevistados se eles consideram que o ruído interfere na sua qualidade de vida e $73 \%$ afirmaram que sim. Apesar disso, somente $13 \%$ previnem-se contra ele, evitando locais barulhentos e o uso de equipamentos eletrônicos em volume alto dentro de casa.

Nota-se, portanto, a necessidade de conscientização da população exposta ao ruído para os efeitos do mesmo sobre a sua saúde e qualidade de vida, pois a preocupação ambiental, segundo Floriani (2004), não está automaticamente relacionada com a magnitude do dano, mas com o significado que este tem para a sociedade. Neste sentido, informar é o melhor caminho.

A noção de prazer e desprazer é muito subjetiva e está diretamente relacionada a sensações físicas e psíquicas de uma pessoa. Dependendo da necessidade e desejo, há momentos do dia ou mesmo da vida em que este ou aquele ambiente causa ou não prazer.

Quando o ambiente é destinado ao descanso, como na nossa casa, somos exigentes, preferimos lugares confortáveis. De acordo com Schmid (2005), a casa, local que escolhemos para morar, oferece conforto e consolo ao ser humano, na medida em que atende a um conjunto de necessidades básicas de segurança e envolvimento. Uma casa deve ser confortável acusticamente e a OMS (1980) estabelece que os níveis de ruído não devem ultrapassar os 45-50 dB(A).

O que já pudemos constatar nesta pesquisa é que a população está exposta aos riscos da poluição sonora mesmo dentro de suas casas, o que nos permite concluir que, em alguns momentos do dia, este local deixa de ser o ambiente que conforta e acolhe para tornar-se um ambiente desagradável.

Eu adorava este lugar até construírem o terminal de ônibus. Moro aqui há 30 anos e era muito tranquilo. Lembro quando existiam muitas chácaras e sítios, depois abriram as rápidas e construíram os terminais. $\mathrm{O}$ barulho aumentou, mas nada se compara com o que é hoje. Posso dizer que é infernal (Sandra, 70 anos, ponto 6).

Infelizmente, o ruído urbano é um mal ecológico presente nas grandes cidades devido ao modelo de desenvolvimento urbano que a maioria das cidades ocidentais contemporâneas seguiu. Como sinais que marcam este modelo 
podemos citar: o crescimento acelerado; o privilegiamento dos automóveis e sua circulação no espaço urbano; a concentração da produção, comércio e serviços; as residências localizadas longe dos ambientes de trabalho. A população entrevistada nesta pesquisa afirmou perceber este mal.

Porém, no decorrer da entrevista, apesar da citação acima descrita e apesar de saberem da presença do ruído em suas casas, apenas três pessoas afirmaram que se mudariam do lugar por causa do ruído, evidenciando, em suas falas, uma visão topofóbica.

Podemos aplicar aqui o conceito de topofilia (TUAN, 1980), isto é, verificamos o elo afetivo entre a pessoa e o lugar ou ambiente físico. A ideia de que a casa traz mais vantagens que desvantagens para os entrevistados revela que as experiências agradáveis estão sendo valorizadas em detrimento dos aspectos negativos relatados.

Desta forma, podemos concluir, considerando as respostas encontradas nesta pesquisa, que o ruído não é um elemento presente na natureza que altere a relação topofílica com a região.

Eu gosto de morar aqui. Moro sozinha, mas por perto tem meus pais e minha irmã, com um monte de sobrinhos. Por isso não mudaria (Silvia, 31 anos, ponto 58).

Moro aqui em Curitiba há 8 anos, vim do interior do Paraná, Ribeirão Claro, onde tudo é muito quieto. Eu acho o barulho aqui muito forte, principalmente no começo da noite. Mas não me mudaria, pois isso tudo é muito moderno. É fácil ir para o trabalho, é seguro, não tenho medo de voltar da aula à noite (Juliane, 28 anos, ponto 84).

Eu não saio mais daqui. Apesar de ter barulho de ônibus e caminhão, a maior parte do tempo é tranquilo, gosto daqui (Anita, 54 anos, ponto 93).

Embora exista a consciência de que no atual endereço existe o ruído, as falas das pessoas evidenciaram questões afetivas e experiências positivas do convívio social, dentro de uma visão topofílica, nas diferentes faixas etárias entrevistadas.

Considerando as análises realizadas de que os locais onde estas pessoas moram oferecem aspectos agradáveis, que superam as dificuldades apresentadas pelo ruído, e nos reportando novamente ao fato de a poluição sonora não degradar o ambiente em si, apesar de alterar e degradar a qualidade de vida das pessoas, pode-se levantar três hipóteses que podem servir de base para novos estudos na área.

Primeiro: quando se trata de poluição, nossos sentidos estão mais atentos à fumaça e águas sujas do que, necessariamente, ao ruído, e a mídia teria grande influência sobre este aspecto, já que é comum a divulgação de eventos onde a poluição do ar e da água causa sérios transtornos para a comunidade, em todo o mundo.

Segundo: vivemos numa sociedade que cultua o ruído e estamos acostumados com ele. Em alguns momentos ele nos causa prazer.

Terceiro: a ideia de inevitabilidade do progresso e da modernidade está condicionando o modo de viver urbano, com meios de transporte barulhentos (ônibus, caminhões, carros). Hoje, a exposição a níveis deletérios de ruído é natural para as pessoas que vivem em uma cidade "moderna".

\section{Considerações finais}

A poluição sonora é um dos problemas ambientais graves nos grandes centros urbanos e uma ameaça constante ao homem - e a análise deste evento e das percepções de um grupo de pessoas que estão expostas a ele nos Setores Especiais Estruturais de Curitiba revelou que a poluição sonora tem acompanhado o processo de expansão urbana. Os espaços ocupados pelo homem nas grandes cidades estão permeados pelo ruído, principalmente onde o tráfego de veículos é intenso.

$\mathrm{O}$ homem, ao atuar sobre o meio físico e introduzir novos elementos, cria impactos de diversas ordens, dentre eles o ruído e, para que possamos criar parâmetros cuja finalidade seja combatê-lo, há que se conhecer as relações existentes entre diversas variáveis, dentre elas a percepção da população.

Embora exista na cidade de Curitiba legislação específica que regula os limites de emissão de ruídos e estabelece medidas de proteção para a coletividade, o que se constata é que o ruído urbano encontra-se acima dos níveis recomendados pelas normas legais vigentes, em especial, nos SEE.

Moradores destes setores percebem o ruído como fonte geradora de desconforto. Porém, esta percepção parece se dar apenas em nível intelectual (insight intelectual) e não de emoção (insight emocional), pois verificamos que a amostra conhece o ruído e seus efeitos, mas não toma medidas preventivas em relação a ele. 
Espontaneamente, $89 \%$ da amostra apontaram o ruído como fator negativo presente no local onde moram e, quando sensibilizada, $100 \%$ da amostra referiu que o ruído existe e interfere na sua qualidade de vida. Esta homogeneidade de percepção das pessoas foi considerada interessante e justificamos a ocorrência, já que, apesar de ser um processo mental individual, as percepções comuns a diversas pessoas em uma coletividade também podem ser observadas. Este tipo de informação é de extrema importância quando se busca subsídios que visem nortear ações sobre o meio ambiente.

Além da homogeneidade das respostas, observamos que a percepção do ruído suplantou a percepção de outros problemas socioambientais. Os entrevistados identificam o ruído como fator negativo em maior grau que o problema gerado pelo intenso tráfego de veículos, a segurança e a violência - fatores que marcam as grandes cidades atualmente. Concluímos que o ruído foi relacionado preferencialmente como um fator negativo, em detrimento aos demais, por estarmos pesquisando uma população que habita regiões qualificadas da cidade de Curitiba.

Como a população entrevistada está exposta aos riscos da poluição sonora, mesmo dentro de suas casas, concluímos que, em alguns momentos do dia, este local deixa de ser o ambiente que conforta e acolhe para tornar-

\section{Referências}

AlvareZ, A. M. Processamento auditivo. Curso teórico ministrado em Curitiba, 2006.

BARBOSA, W. Aspectos do ruído comunitário de Curitiba. Dissertação (Mestrado) - Programa de Pós-Graduação do Departamento de Engenharia Mecânica da UFPR. Curitiba: UFPR, 1992.

BUTTIMER, A. Apreendendo o dinamismo do mundo vivido. In: Perspectivas da Geografia. São Paulo: Difusão, 1982.

CURITIBA. Lei Municipal 10.625, de dezembro de 2002. Prefeitura Municipal de Curitiba, Secretaria Municipal do Meio Ambiente, 2002.

DEL RIO, V. V. Cidade da mente: cidade real. In: DEL RIO, V. V.; OLIVEIRA, L Percepção ambiental: a experiência brasileira. São Paulo: Studio Nobel, 1996.

; OLIVEIRA, L. Percepção ambiental: a experiência brasileira. São Paulo: Studio Nobel, 1996. -se um ambiente desagradável. Porém, considerando as respostas encontradas nesta pesquisa, verificamos que o ruído não é um elemento presente na natureza que altere a relação topofílica com o lugar vivido.

Concluímos que é possível viver em ambientes insalubres do ponto de vista auditivo, pois as pessoas se acostumam com a presença do ruído e não se dão conta dos seus efeitos negativos sobre a qualidade de vida e sobre a própria saúde.

Entendemos que a ausência de percepção sobre os efeitos do ruído tem relação com o significado que este tem para a sociedade e, desta forma, informar e educar a população é o melhor caminho.

Pudemos constatar que o ruído não é, efetivamente, considerado um fator de risco pela comunidade pesquisada. Mesmo sabedores de que o ruído urbano existe e que ele traz prejuízos à saúde, a maioria da amostra não reage ao fato, agindo de maneira fatalista ou com sentimento de inevitabilidade. Torna-se necessária, desta maneira, a formação de opinião e, para que isso ocorra, o fenômeno ruído deve ser mais bem observado pelos gestores e pela comunidade. As informações geradas devem ser disponibilizadas para que as pessoas a utilizem, em comunicações privadas ou não. Deve-se melhorar a comunicação coletiva por sistemas educativos ou de comunicação de massa.

FLORIANI, D. Conhecimento, meio ambiente e globalização. Curitiba: Juruá, 2004.

. Diálogo de saberes. Entrevista concedida à TV Educativa de Curitiba em abril de 2007. Curitiba, 2007.

FOIN, T. C. Ecological systems and the environment. Boston: Houghton Mifflin Company, 1976.

GIDDENS, A. Modernidade e identidade. Rio de Janeiro: Zahar Editores, 2002.

GOLDBLAT, D. Teoria social e ambiente. Lisboa: Instituto Piaget, 1996.

GOMES-FILHO, J. Gestalt do objeto: sistema de leitura visual da forma. São Paulo: Escrituras, 2000.

GOODEY, B.; GOLD, J. Geografia do comportamento e da percepção. Belo Horizonte: UFMG, 1986. 
HEEMANN, A.; HEEMANN, N. Natureza e percepção de valores. Desenvolvimento e Meio Ambiente, v. 7, 2003.

HUNGRIA, H. Otorrinolaringologia. Rio de Janeiro: Guanabara Koogan, 1995.

KAPLAN, H. I.; SADOCK, B. J.; GREEB, J. Compêndio de psiquiatria: ciências do comportamento e psiquiatria clínica. Porto Alegre: Artes Médicas, 1997.

KOZEL-TEIXEIRA, S. Das imagens à linguagem do geográfico: Curitiba "A Capital Ecológica". Tese (Doutorado) - Programa de Pós-Graduação da Universidade de São Paulo. São Paulo: USP, 2001.

LACERDA, A. B. M.; MAGNI, C.; MORATA, T. C.; MARQUES, J.; ZANNIN, P. T. Reações psicossociais ao ruído urbano. Revista Ambiente e Sociedade, v. 8, n. 2, dezembro de 2005.

LACERDA, A. B. M.; RIBAS, A.; MENDES, J.; ANDRADE, P. Noise level and its perception by commuters in urban buses of Curitiba. Canadian Acoustic, v. 32, n. 4, p. 53-59, 2004.

LENT, R. Cem bilhões de neurônios. São Paulo: Atheneu, 2005.

LOWENTHAL, D. Geografia, experiência e imaginação: em direção a uma geografia epistemológica. In: Perspectivas da Geografia. São Paulo: Difusão, 1982.

MAY, D. Handbook of noise assessment. New York: Litton, 1978.

MERLEAU-PONTY, M. Fenomenologia da percepção. São Paulo: Martins Fontes, 1999.

MERLUZZI, F. Patologia da rumore. Pádua: Piccin Editore, 1981.

NBR 10151. Acústica - Avaliação do ruído em áreas habitadas, visando ao conforto da comunidade. Rio de Janeiro: ABNT, 2000.

NBR 10152. Acústica - Avaliação do ruído ambiente em recintos de edificações visando ao conforto dos usuários. Rio de Janeiro: ABNT, 2000.

OLIVEIRA, I.; MOCELIN, J.; RIBAS, A. A percepção da poluição sonora numa região da cidade de Curitiba. Rev. Fonoaudiologia Brasil, v. 2, 2005.

ORGANIZATION MONDIALE DE LA SANTÉ. Critères d'hygiène de l'environnement 12. Genève: OMS, 1980.

OSOL, A. Dicionário médico: Blakiston. São Paulo: Andrei Editora, s.d.

PONTING, C. Uma história verde do mundo. Rio de Janeiro: Civilização Brasileira, 1995.
RIBAS, A. Reflexões sobre o ambiente sonoro da cidade de Curitiba: a percepção do ruído urbano e seus efeitos sobre a qualidade de vida de moradores dos setores especiais estruturais. Tese (Doutorado) - UFPR. Curitiba, UFPR, 2007.

; NAZARENO, E. R; SCHIMD, A. L. A percepção dos efeitos da poluição sonora em uma região da cidade de Curitiba. OIUDSMA. Anais. Curitiba: 2006.

RUSSEL, B. O conhecimento humano. São Paulo: Companhia Editora Nacional, 1958.

SANTOS, U.; MORATA, T. Efeitos do ruído na audição. In: SANTOS, U. Ruido: riscos e prevenção. São Paulo: Hucitec, 1994.

SANCHES, F. A reinvenção das cidades para um mercado mundial. Chapecó: Argos, 2003.

SATTLER, A. M. Avaliação de impacto de ruído determinado por sistemas binários de tráfego. ENCAC, V. Anais. Fortaleza, 1999.

SCHMID, A. L. A ideia de conforto. Reflexões sobre o ambiente construído. Curitiba: Pacto Ambiental, 2005.

SHAFER, R. M. A afinação do mundo: uma exploração pioneira pela história passada e pelo atual estado do mais negligenciado aspecto do nosso ambiente: a paisagem sonora. São Paulo: UNESP, 2001.

SOULE, M. Biodiversidade. Rio de Janeiro: Nova Fronteira, 1997.

SOUZA, D. S. Instrumentos de gestão da poluição sonora para a sustentabilidade das cidades brasileiras. Tese (Doutorado) - Programa de Pós-Graduação em Energia da UFRJ. Rio de Janeiro: UFRJ, 2004.

TUAN, Y. F. Topofilia: um estudo da percepção, atitudes e valores do meio ambiente. São Paulo: DIFEL, 1980.

ZANELLA, M. E. Inundações urbanas em Curitiba: impactos, riscos e vulnerabilidade socioambiental no bairro Cajuru. Tese (Doutorado) - Programa de Pós-Graduação em Meio Ambiente e Desenvolvimento - UFPR. Curitiba: UFPR, 2006.

ZANNIN, P. T.; DINIZ, F. B.; BARBOSA, W. A. Environmental noise pollution in the city of Curitiba, Brazil. Applied Acoustics, v. 63, p. 351-358, 2002.

Recebido em setembro de 2009. Aceito em março de 2010. Publicado em dezembro de 2010. 